\title{
Vascular endothelial cadherin and $\beta$-catenin in human fetoplacental vessels of pregnancies complicated by Type 1 diabetes: associations with angiogenesis and perturbed barrier function
}

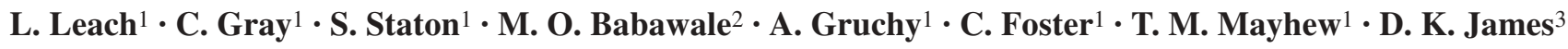 \\ ${ }^{1}$ Centre for Integrated Systems Biology and Medicine, School of Biomedical Sciences, University of Nottingham, UK \\ 2 School of Molecular Medical Sciences, University of Nottingham, UK \\ ${ }^{3}$ School of Human Development, Faculty of Medicine and Health Sciences, University of Nottingham, UK
}

\section{Abstract}

Aims/hypothesis. Increased angiogenesis of fetoplacental vessels is a feature of pregnancies complicated by Type 1 diabetes mellitus, but the underlying molecular mechanisms are unknown. This investigation tests whether the diabetic maternal environment alters the phenotypic expression of placental vascular endothelial cadherin and $\beta$-catenin, which have been implicated as key molecules in barrier formation and angiogenesis in the endothelium.

Methods. Term placental microvessels from normal pregnancies $(n=8)$ and from those complicated by Type 1 diabetes $(n=8)$ were perfused with $76-\mathrm{M}_{\mathrm{r}}$ dextran tracers $(1 \mathrm{mg} / \mathrm{ml})$ and subjected to immunocytochemistry, immunoblotting and microscopy. Junctional integrity, localisation and phosphorylation were investigated along with total protein levels of vascular endothelial cadherin, $\beta$-catenin and vascular endothelial growth factor. Stereological sampling and estimation tools were used to quantify aspects of angiogenesis and endothelial proliferation.

Results. In the Type 1 diabetic placentae, junctional localisations of vascular endothelial cadherin and $\beta$-catenin altered significantly, with more than $50 \%$ of microvessels showing complete loss of immunoreactivity and with no overall loss of total protein. Tracer leakage was associated with these vessels. There was a two- to three-fold increase in vessels showing junctional phospho-tyrosine immunoreactivity and hyperphosphorylated $\beta$-catenin. Vascular endothelial growth factor levels were higher in these placentae. A fourfold increase in endothelial proliferation was observed, along with an increase in total length of capillaries without any change in luminal diameter.

Conclusions/interpretation. Molecular perturbations of vascular endothelial cadherin and $\beta$-catenin occur in fetoplacental vessels of pregnancies complicated by Type 1 diabetes. Phosphorylation and loss of these molecules from the adherens junctional domains may be influenced in part by the elevated levels of vascular endothelial growth factor in the placenta. Perturbations of the junctional proteins may explain the observed breach in barrier integrity and may contribute to the mechanisms that drive proliferation and increases in capillary length.

Keywords Angiogenesis $\cdot \beta$-catenin - Diabetes · Endothelium · Placenta $\cdot$ Tracer leakage $\cdot$ Vascular endothelial cadherin - Vascular endothelial growth factor
Received: 22 September 2003 / Accepted: 18 November 2003

Published online: 17 March 2004

(C) Springer-Verlag 2004

L. Leach $(\bowtie)$

Centre for Integrated Systems Biology and Medicine,

School of Biomedical Sciences, University of Nottingham, UK

E-mail: lopa.leach@nottingham.ac.uk

Abbreviations: VE-cadherin, vascular endothelial cadherin . VEGF, vascular endothelial growth factor - PECAM-1, platelet endothelial adhesion molecule-1 - PCNA, proliferating cell nuclear antigen - TRITC, tetramethylrhodamine isothiocyanate

\section{Introduction}

The human placenta contains a complex vascular system, which is entirely fetal in origin and continuous with the vasculature of the developing fetus. These fetoplacental vessels are found in chorionic villi, which are bathed in maternal blood, and this arrangement permits the efficient exchange of solutes and gases between the maternal and fetal circulations without the two intermingling. However, this juxtaposition leaves the development, growth and remod- 
elling of the fetoplacental vessels, which are driven by fetal need, vulnerable to the immediate environment of the maternal and fetal blood. Any pathological alterations in maternal haemodynamics, in maternal blood properties (such as hypoxia or hyperglycaemia) or in growth factors including vascular endothelial growth factor (VEGF), cytokines and inflammatory mediators may directly influence the growth, maintenance and functioning of these fetoplacental vessels. Furthermore, it is possible that changes in fetoplacental vessels predict or reflect those in the vasculature of the developing fetus.

Fetal well-being and optimal growth depend on successful development of an effective fetoplacental circulation. Formation of fetoplacental vessels (vasculogenesis) occurs in the first four to five weeks of pregnancy, whilst elaboration of the microvascular beds and formation of new from pre-existing capillaries (angiogenesis) continues into the last trimester of pregnancy [1]. The vascular changes influence the development of the chorionic villi, and the phased formation of stem, immature intermediate and mature intermediate villi eventually leads to a multitude of terminal villi which arise through bulging of coiled capillary loops $[1,2]$. In pregnancies complicated by Type 1 diabetes, these stages of vascular and villous development occur in and are vulnerable to the diabetic milieu.

Various pathological alterations in the diabetic placenta have been reported, including hypertrophy, villous oedema, hypovascularity and immaturity, and proliferation of the capillary endothelium [3]. Increases in the volume, surface area and length of fetal capillaries (enhanced angiogenesis) have also been reported in the well-controlled diabetic placenta [4], and these changes are accompanied by greater fetal and total diffusive conductances [5]. Increased angiogenesis is a common feature of diabetic vasculopathy, particularly manifest in diabetic retinopathy [6] where increased vascular leakage is a complication. The molecular organisation and integrity of the endothelial junctions of capillaries in the Type 1 diabetic placenta have not been well explored. Furthermore, the molecular and cellular mechanisms regulating angiogenesis and barrier function in pregnancies complicated by pre-existing diabetes remain unclear.

The adherens junctional molecules, vascular endothelial cadherin (VE-cadherin) and $\beta$-catenin are important for formation of continuous monolayers, regulation of vascular permeability, endothelial survival, tubulogenesis and initiation of angiogenesis [7, 8, 9]. They play a key role in placental vascular development in humans, as shown by the early expression of these molecules in haemangioblasts of the first trimester placenta [10]. Differential expression of these molecules in normal and histamine-perfused term placentae indicates their importance in regulating vascular permeability and plasticity $[11,12]$. We have pre- viously shown that the loss of junctional VE-cadherin and $\beta$-catenin is a very early event in VEGF-induced angiogenesis in human umbilical vein cells [13]. VEGF has been shown to elicit increased nuclear localisation of $\beta$-catenin as well as increased cyclin D1 in the umbilical vein cells, which correlated with increased proliferation [14]. Moreover, VEGF-induced tyrosine phosphorylation of VE-cadherin and $\beta$-catenin leads to junctional alterations and increased permeability to macromolecules $[15,16]$. Perturbation of the junctional molecules may be a complication of diabetes mellitus with resultant leaky angiogenic vessels. This is certainly a feature of diabetic retinopathy where reduced occludin content has been correlated with loss of blood-retinal barrier [6, 17].

The hypothesis linking adherens junctional molecules with angiogenesis comes from several studies in which releasing $\beta$-catenin from cell junctions resulted in active cytoplasmic pools of $\beta$-catenin. This free $\beta$-catenin can translocate to the nucleus and modulate cell transcription [18]. Negative regulation of this pathway can occur through sequential phosphorylation of $\beta$-catenin by casein kinase- $1 \alpha$ (at serine 45 ), followed by phosphorylation through glycogen synthase kinase- 3 in complex with adenomatous polyposis coli and axin, with resultant targeting of $\beta$-catenin for ubiquitination and degradation [19]. Similarly, an increase in VE-cadherin causes the recruitment of 'free' cytoplasmic $\beta$-catenin by cell-cell junctions and thereby inhibits signalling and lymphoid enhancer binding factor/transcription factor transactivation [20, 21]. Indeed, VE-cadherin expression and clustering at intercellular junctions (contact inhibition) blocks the proliferative response of the endothelial cells to VEGF, with the inhibition of VEGF receptor-2 tyrosine phosphorylation contributing to this effect [22].

It is not known whether alterations in VE-cadherin and $\beta$-catenin occur in blood vessels in the human Type 1 diabetic placenta. Certainly, short-duration diabetes, such as gestational diabetes, does result in significant loss of surface expression of junctional adhesion molecules [23]. The possible functional consequences of such alterations, e.g. increased vascular leakiness or angiogenesis, have not been demonstrated in pre-gestational diabetes.

In the normal placenta, the vascular endothelium provides a substantial barrier to materno-fetal transport [24]. The paracellular cleft, containing well-differentiated junctions, is the preferred route for transport of small $\left(<70 \mathrm{M}_{\mathrm{r}}\right)$ hydrophilic solutes. The extent to which the diabetic placental endothelial barrier restricts movement of macromolecules is unknown.

The aim of this study was to investigate the molecular organisation of the adherens junction in placentae from Type 1 diabetic patients, paying special attention to the expression of VE-cadherin and $\beta$-catenin. The proliferative and angiogenic status of these vessels, as well as their leakiness to perfused large molecules 
(76- $\mathrm{M}_{\mathrm{r}}$ dextran), was also examined. To understand the mechanisms behind any alterations of the adherens junctional proteins, we monitored the phosphorylation status of junctional molecules (specifically $\beta$-catenin) as well as placental VEGF levels. Finally, we investigated the extent to which vascular disturbances correlated with maternal glycaemic control and duration of disease.

\section{Subjects and methods}

\section{Tissue selection}

The study was based on pregnancies monitored at Queen's Medical Centre, Nottingham, UK. Local ethics committee approval and written patient consent were obtained. Patients in the experimental group ( $n=8$; patients $\mathrm{I}-\mathrm{P}$ in tables) were Type 1 diabetic patients who had become pregnant after diagnosis, and only patients with no history of microvascular complications (retinopathy, nephropathy) were included. Treatment throughout gestation was managed in accordance with established protocols. All patients continued with their insulin regime for adequate glucose control. Patients in the control group ( $n=8$; patients $\mathrm{A}-\mathrm{H}$ in tables) had normal (uncomplicated) term pregnancies with no microvascular complications. Patients in both groups were of similar age and were non-smokers with no history of hypertension or pre-eclampsia. In both groups, the birthweights of the offspring were recorded and their centiles calcu-

Table 1. Maternal, neonatal and placental characteristics of the control group: normal uncomplicated pregnancies

\begin{tabular}{lllll}
\hline Patients & $\begin{array}{l}\text { Birthweight } \\
(\mathrm{kg})\end{array}$ & Centile & $\begin{array}{l}\text { Placental } \\
\text { weight } \\
(\mathrm{g})\end{array}$ & $\begin{array}{l}\text { Gestational } \\
\text { age at delivery } \\
\text { (weeks) }\end{array}$ \\
\hline A & 3.70 & 76 & 675 & 37 \\
B & 3.86 & 86 & 902 & 38 \\
C & 2.96 & 28 & 562 & 39 \\
D & 4.00 & 62 & 670 & 41 \\
E & 3.43 & 80 & 695 & 38 \\
F & 3.67 & 80 & 695 & 38 \\
G & 3.37 & 82 & 650 & 38 \\
H & 3.06 & 75 & 515 & 38 \\
\hline
\end{tabular}

lated using local, customised charts which made allowances for maternal size, ethnicity and parity [25]. The clinical details of patients are shown in Tables 1 and 2 .

Tissue processing. Placentae were collected immediately after delivery (elective Caesarean section in the last trimester), and the umbilical cord clamped to prevent blood loss from and collapse of the fetoplacental vessels. Once in the laboratory, the wet weights of the placentae were recorded. Each placenta was placed in a chamber maintained at $37^{\circ} \mathrm{C}$ and perfused according to a well-established procedure [26]. Briefly, the chorionic artery and corresponding vein of a randomly selected lobule were cannulated and connected to a fetal circuit, which included a pressure monitor, reservoir and peristaltic pump. The maternal circulation was simulated by introducing five catheters into the intervillous space from the maternal side of the same lobule. The catheters were connected to a similar independent maternal circuit. Normal and diabetic placentae were perfused for a 20-min equilibration period (to reverse any post-parturition hypoxic changes) with oxygenated medium 199 (with added albumin and high- $\mathrm{M}_{\mathrm{r}}$ dextran; Sigma, Poole, UK). Maternal and fetal circulations were perfused independently with open circuits. Perfusion parameters were as follows: fetal flow $5 \mathrm{ml} / \mathrm{min}$, maternal flow $18 \mathrm{ml} / \mathrm{min}$, fetal pressure 40 to $80 \mathrm{mmHg}$, and maternal pressure $<20 \mathrm{mmHg}$. After equilibration, fetal vessels were perfusion-fixed for 30 min with $1 \%$ paraformaldehyde in phosphate buffer $(0.1 \mathrm{~mol} / \mathrm{l}, \mathrm{pH} 7.3)$, excised and immersion-fixed for a further $120 \mathrm{~min}$. Biopsies of roughly $2 \mathrm{~cm}^{3}$ were taken and frozen in nitrogen-cooled isopentane for subsequent immunocytochemistry and immunoblotting. Tissue biopsies were also processed for transmission electron microscopy.

Tracer leakage studies. From the available material, five normal placentae and five diabetic placentae were collected and perfused as described above. However, after the 20-min equilibration period, the fetal reservoir was switched to a closed circuit containing $100 \mathrm{ml}$ of oxygenated medium 199 perfusate. A bolus of tracer, tetramethylrhodamine isothiocyanate (TRITC)-conjugated dextran (76 $\mathrm{M}_{\mathrm{r}}$; Sigma, St. Louis, Mo., USA), was added to the fetal reservoir to make a final concentration of $1 \mathrm{mg} / \mathrm{ml}$. The lobule was then perfused for a further 10 min. The maternal circuit remained open and tracer free. After $10 \mathrm{~min}$, the fetal circuit was switched to one containing $1 \%$ paraformaldehyde in PBS and perfusion-fixed for a further $30 \mathrm{~min}$. The tissue was then excised, cut into cubes of roughly $5 \mathrm{~mm}$ and immersion-fixed for $2 \mathrm{~h}$ in the same fixative as above. Villous trees were randomly cut, washed and examined

Table 2. Maternal, neonatal and placental characteristics of the study group: pregnancies complicated by Type 1 diabetes mellitus

\begin{tabular}{|c|c|c|c|c|c|c|c|}
\hline \multirow[t]{2}{*}{ Patients } & \multirow{2}{*}{$\begin{array}{l}\text { Birthweight } \\
(\mathrm{kg})\end{array}$} & \multirow[t]{2}{*}{ Centile } & \multirow{2}{*}{$\begin{array}{l}\text { Placental } \\
\text { weight } \\
(\mathrm{g})\end{array}$} & \multirow{2}{*}{$\begin{array}{l}\text { Gestational } \\
\text { age } \\
\text { (weeks) }\end{array}$} & \multirow{2}{*}{$\begin{array}{l}\text { Disease } \\
\text { duration } \\
\text { (years) }\end{array}$} & \multirow{2}{*}{$\frac{\mathrm{HbA}_{1} \mathrm{c}}{\mathrm{T} 2(\%)}$} & \multirow{2}{*}{$\frac{\mathrm{HbA}_{1} \mathrm{c}}{\mathrm{T} 3(\%)}$} \\
\hline & & & & & & & \\
\hline $\mathrm{J}$ & 3.30 & 98 & 700 & 36 & 26 & 6.7 & 6.8 \\
\hline $\mathrm{K}$ & 3.50 & 97 & 578 & 38 & 10 & 7.6 & 8.5 \\
\hline $\mathrm{L}$ & 5.05 & 99 & 1208 & 38 & 1 & 6.7 & 6.5 \\
\hline $\mathrm{O}$ & 3.58 & 97 & 1034 & 37 & 1 & 6.2 & 6.2 \\
\hline $\mathrm{P}$ & 3.74 & 97 & 560 & 36 & 15 & 7.4 & 7.0 \\
\hline
\end{tabular}

$\mathrm{HbA}_{1} \mathrm{c}$ was measured at the end of the second trimester (T2) and at end of the third trimester $(\mathrm{T} 3)$. HbA 1 c $<6.8 \%$ was considered normal 
with confocal scanning microscopy to observe any leakage of the tracer from the vascular compartment. Where present, this was evident as 'hot spots' of tracers trapped in the perivascular abluminal interstitial tissue underlying the trophoblast. Remaining biopsies (randomly chosen) were frozen as described above and used for immunolabelling studies.

\section{Immunofluorescence}

Antibodies. Primary antibodies used were mouse anti-human monoclonal antibody to VE-cadherin, clone 55-7H1 $(5 \mu \mathrm{g} / \mathrm{ml}$; BD Pharmigen, San Diego, Calif., USA); rabbit polyclonal antibody to $\beta$-catenin $(5 \mu \mathrm{g} / \mathrm{ml}$; Sigma); rabbit anti-phospho- $\beta$ catenin, Thr41/Ser45 (10 $\mu \mathrm{g} / \mathrm{ml}$; Cell Signaling Technology, Beverly, Mass., USA); rabbit phospho-tyrosine $(10 \mu \mathrm{g} / \mathrm{ml}$; BD Transduction Laboratories, Lexington, Ky., USA); mouse monoclonal antibody to proliferating cell nuclear antigen (PCNA), clone PC10 (5 $\mu \mathrm{g} / \mathrm{ml}$; Sigma); mouse monoclonal antibody to human VEGF $(5 \mu \mathrm{g} / \mathrm{ml}$; R\&D Systems, Minneapolis, Minn., USA); anti-platelet endothelial adhesion molecule-1 (PECAM-1; $5 \mu \mathrm{g} / \mathrm{ml}$; R\&D Systems) and anti-thrombomodulin, QBEND-40 (4 $\mu \mathrm{g} / \mathrm{ml}$; Serotec, Oxford, UK) and $\beta$-actin (ascitic fluid, 1:8000; Abcam, Cambridge, UK). Secondary antibodies were fluorescein isothiocyanate-conjugated goat anti-mouse IgG (11 $\mu \mathrm{g} / \mathrm{ml}$; Sigma), TRITC-conjugated goat anti-rabbit IgG $(50 \mu \mathrm{g} / \mathrm{ml}$; Sigma) or peroxidase-conjugated sheep anti-mouse IgG ( $2 \mu \mathrm{g} / \mathrm{ml}$; Sigma).

Immunostaining. Frozen sections of placental tissue were air-dried, washed in PBS ( $\mathrm{pH} 7.2$ ), permeabilised with $0.1 \%$ Triton X-100 for $10 \mathrm{~min}$, blocked with 5\% normal human serum (30 min, room temperature) and incubated with the appropriate antibody overnight at $4{ }^{\circ} \mathrm{C}$. Sections were thoroughly washed in PBS $+0.1 \%$ BSA and incubated with the appropriate secondary antibody for $2 \mathrm{~h}$ at $37^{\circ} \mathrm{C}$.

For PCNA immunoreactivity, the Triton X-100 detergent incubation step was increased to $30 \mathrm{~min}$ at $4{ }^{\circ} \mathrm{C}$ to remove the non-S-phase PCNA fraction [27]. The primary PC10 antibody was also diluted in Leucoperm permeabilisation reagent $\mathrm{B}$ (Serotec) to increase antibody access to the nucleus.

Microscopy. Immunoreactivities were assessed using a Nikon fluorescence microscope (Nikon, Welwyn Garden City, UK) and a Leica TCS4D laser scanning confocal microscope (Leica Microsystems, Milton Keynes, UK). Optical sections ( 0.4 to $0.8-\mu \mathrm{m}$ intervals) were stored and manipulated using the accompanying software. Maximal intensity projections and single optical sections (same laser settings, same depth of sectioning) were compiled to compare fluorescent intensities between normal and Type 1 diabetic placental immunoreactivities.

\section{Vessel sampling}

The relative incidences of vascular profiles showing different junctional immunoreactivities were estimated as described previously by applying random sampling procedures and unbiased profile counting rules [23, 28]. Provided that encounters between section planes and vessels occur at random orientations, these two-dimensional counts also represent the relative lengths in three dimensions of immunostained regions along the entire length of the vascular bed. Using the fluorescence microscope and a grid inserted into the eye-piece, the numbers of vascular profiles showing junctional immunoreactivity on section planes were counted using the unbiased 'forbidden line' counting principle [29]. These were expressed as percent- ages of total vessels counted (all vessels, whether positive or negative for immunoreactivity). To maintain efficiency, no more than 200 sampling items (vascular profiles showing positive immunoreactivity) were counted in each placenta.

Counts of vessels displaying tracer leakage (hot spots) were performed using the principles outlined above. Furthermore, using fluorescein isothiocyanate and TRITC excitation wavelengths as well as confocal microscopy, the counts of vessels showing perivascular hot spots and negative junctional immunoreactivity to anti-VE-cadherin were performed.

A 'two-step' counting procedure was used to quantify, on single sections, the proportion of images of total endothelial cell nuclei showing PCNA immunoreactivity. Once images of PCNA-positive endothelial cell nuclei were counted (by systematic random sampling using unbiased counting frames), sections were remounted with mounting medium containing propidium iodide (Vectashield; Vector Laboratories, Burlingame, Calif., USA), and the same fields of view were relocated in order to count total numbers of endothelial cell nuclei.

\section{Immunoblots}

From each experimental group, 100-mg samples of frozen placental tissue were taken. Tissues were pulverised, placed in $1 \mathrm{ml}$ of sample buffer, homogenised by sonication and stored at $-20^{\circ} \mathrm{C}$. To ensure that the same concentration of protein was present in all samples, a bicinchroninic acid protein assay kit (Pierce-Perbio Science, Cheshire, UK) was also used to equilibrate samples. Samples were separated by SDS-PAGE in $7.5 \%$ gels, transferred onto Immobilon-P membranes (Millipore Corporation, Bedford, Mass., USA), blocked with 3\% BSA in PBS containing Tween-20, and then incubated overnight at $4{ }^{\circ} \mathrm{C}$ with appropriate antibodies (against VEGF, VE-cadherin, $\beta$-catenin, $\beta$-actin, phospho-tyrosine and thrombomodulin). Immunoreactive bands were visualised by using peroxidaseconjugated secondary antibodies and the enhanced chemiluminescence western blot detection system (Amersham, Little Chalfont, UK).

\section{Stereological estimations of capillary dimensions}

As described previously [23], to minimise shrinkage and processing distortions, toluidine blue-stained semi-thin resin sections of placenta were used. Systematic random sampling of fields was achieved using an Olympus microscope (Olympus Danmark, Silkborg, Denmark) with a motorised stage controlled by $x-y$ axis step motors. Selected fields were analysed with test lattices, each of which was superimposed at random. Volume density and length density of fetoplacental vessels were estimated.

The mean luminal 'diameter' of capillaries was estimated by dividing volume density by length density (to obtain mean cross-sectional area) and then calculating the diameter of a circle of equivalent area. Total capillary length in each placenta was calculated by multiplying length density by placental volume. The latter was obtained from placental weight and an empirical estimate of tissue density $\left(1.05 \mathrm{~g} / \mathrm{cm}^{3}\right)$ [5].

\section{Statistics}

Group means and SEMs were calculated for each variable. Values for the percentages of vessels showing immunolocalisation for VE-cadherin, $\beta$-catenin, phospho- $\beta$-catenin and junctional phosphotyrosine were calculated for normal and Type 1 

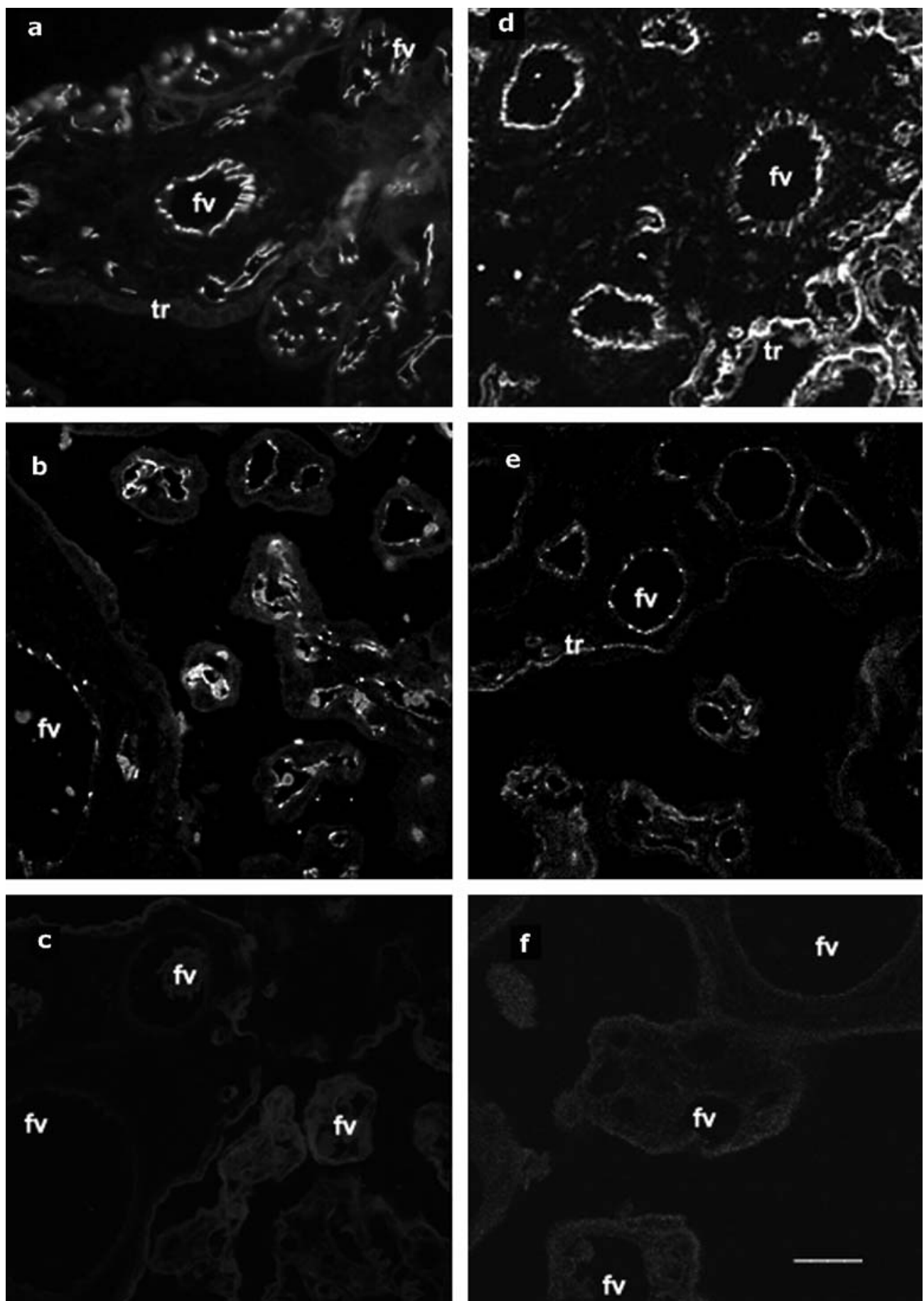

Fig. 1a-f. Confocal fluorescent micrographs of the human term placenta showing localisation of adherens junctional molecules, vascular endothelial (VE)-cadherin and $\beta$-catenin, in placentae from normal pregnancies and those complicated by Type 1 diabetes mellitus. fv, fetoplacental vessels; tr, trophoblast cells; bar $=25 \mu \mathrm{m}$. a, b Maximum-intensity projections of 20 optical slices through $8 \mu \mathrm{m}$, acquired at the same laser power setting. a VE-cadherin in normal term placenta. Immunoreactivity is present as continuous lines corresponding to endothelial paracellular clefts of vessels in longitudinal sections and larger vessels. Microvessel cross sections show a 'beads on a string' arrangement. VE-cadherin is exclusive to endothelial cells; no immunoreactivity is visible in trophoblast cells. b VE-cadherin in the Type 1 diabetic placenta. Immunostaining in fetoplacen-

tal vessels is minimal and weak. c Anti-VE-cadherin immunoreactivity in the Type 1 diabetic placenta; no immunostaining is visible in fetoplacental vessels. d Anti- $\beta$-catenin immunoreactivity in the normal term placenta. $\beta$-catenin can be seen in paracellular clefts of vessels in all villi. Note presence of $\beta$-catenin at the trophoblast layer. e Anti- $\beta$-catenin immunoreactivity in the Type 1 diabetic placenta. Intensity of anti$\beta$-catenin immunoreactivity is reduced; both images represent the same number of optical slices acquired on the same laser setting. Immunoreactivity in the overlying trophoblast layer is still present. f Anti- $\beta$-catenin immunoreactivity in the diabetic placenta, with negative $\beta$-catenin immunoreactivity in fetoplacental vessels 

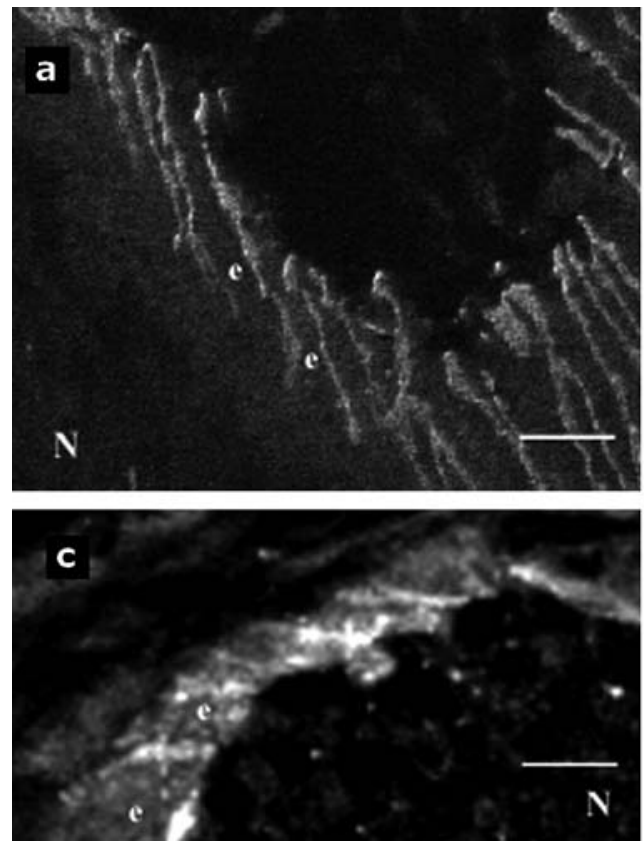

Fig. 2a-d. Combined topographical and scanning confocal micrographs of fetoplacental vessels from normal and Type 1 diabetic placentae, showing immunolocalisation of vascular endothelial (VE)-cadherin and $\beta$-catenin. e, endothelial cell; bar = $10 \mu \mathrm{m}$ unless otherwise stated. a In the normal placenta, VEcadherin is only visible in paracellular clefts between the endothelial cells of a fetoplacental vessel. b In Type 1 diabetic placentae, VE-cadherin immunoreactivity is present in shorter sections of paracellular clefts (background darkened to highlight cleft staining); bar $=15 \mu \mathrm{m}$. c $\beta$-Catenin immunolocalisation in clefts and in the cytoplasm of endothelial cells in a normal placental vessel. d Reduced or negative immunoreactivity in junctional and cytoplasmic regions of a vessel taken from a Type 1 diabetic placenta

diabetic placentae. Student's $t$ test or the Mann-Whitney $U$ test were used to compare groups, and apparent differences were considered to be significant at a probability level of $p<0.05$. Correlations between selected variables and maternal glycated haemoglobin levels were undertaken in each group using Spearman's rank correlation coefficient.

\section{Results}

Analysis of adherens junctional proteins. In term placentae from uncomplicated pregnancies, VE-cadherin, $\beta$-catenin and PECAM-1 were localised to paracellular clefts of all fetoplacental vessels. The same was true for vessels in the Type 1 diabetic group. However, using confocal laser settings identical to those used for observing normal placental sections, confocal microscopy revealed that fluorescence intensities, where present, in single optical sections were greatly reduced in the Type 1 diabetic group (Fig. 1). Higher resolution analyses showed reductions in cytoplasmic and junctional immunostaining of $\beta$-catenin in Type 1 dia-
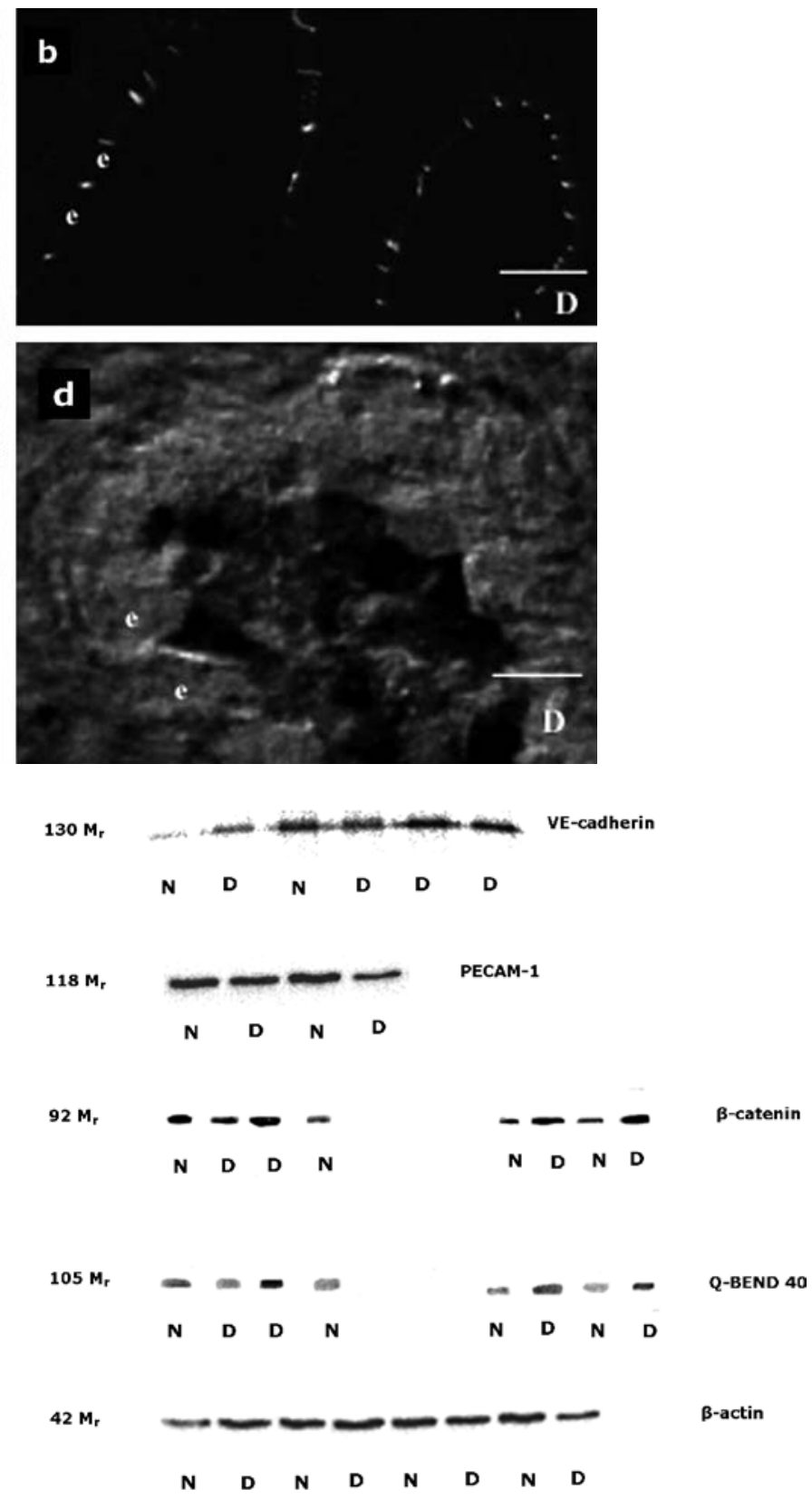

Fig. 3. Expression analyses of adherens junctional molecules, vascular endothelial (VE)-cadherin and $\beta$-catenin, and the transmembrane adhesion molecule, platelet endothelial adhesion molecule (PECAM)-1 in individual normal (N) and Type 1 diabetic (D) placentae. No loss of expression was seen in the diabetic placenta. Expression of thrombomodulin (Q-BEND40) was used as a control endothelial marker. The profile of variation in protein band intensity among the placentae is similar to that of $\beta$-catenin. $\beta$-actin was used as an internal marker and showed no differences between study groups

betic placentae (Fig. 2), whilst the extent of paracellular clefts occupied by the more junctionally exclusive VE-cadherin was greatly reduced in these vessels. Moreover, counts revealed statistically significant differences $(p<0.001)$ between study groups in the percentages of vascular profiles showing junctional im- 

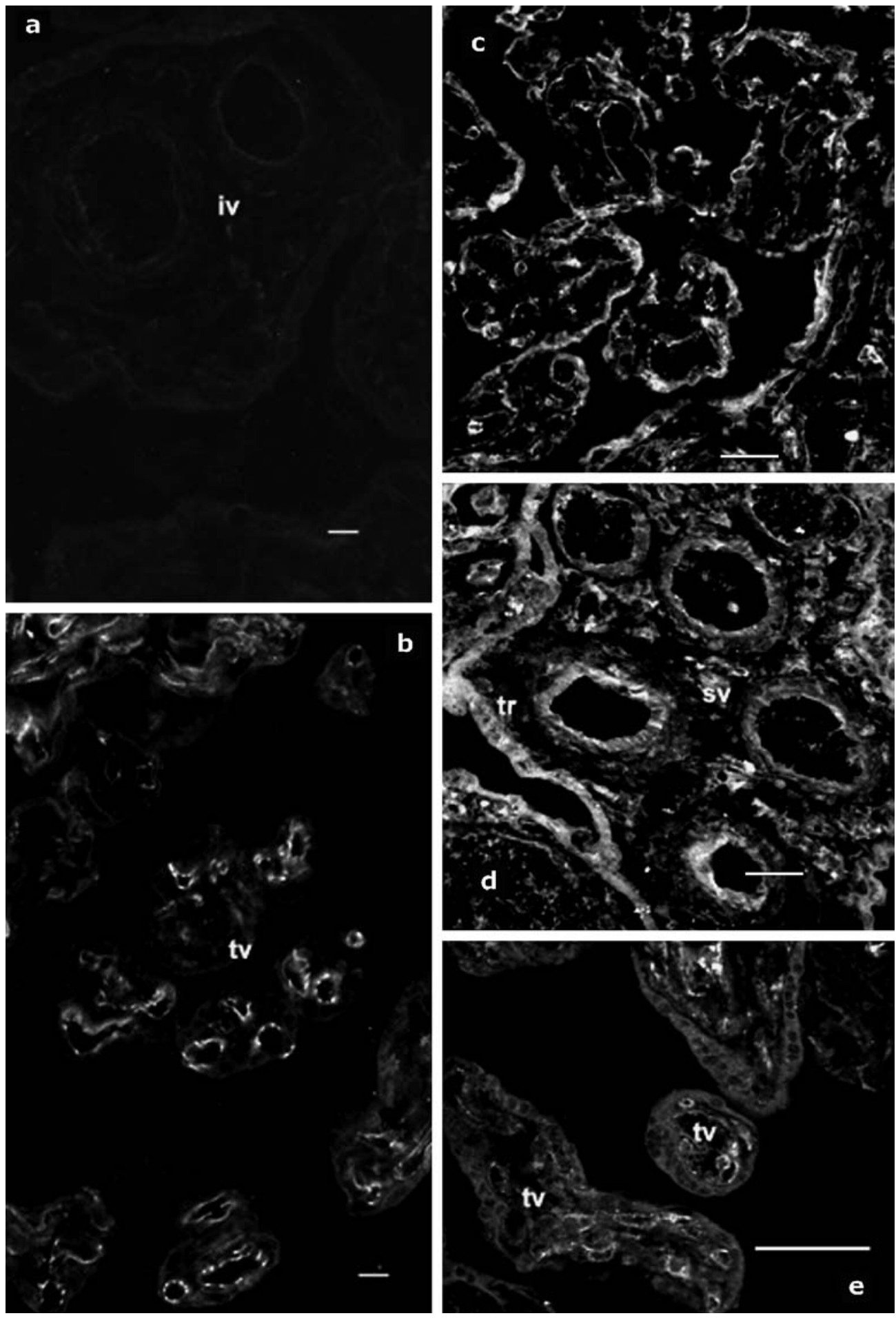

Fig. 4a, b. Confocal micrographs showing anti-phosphotyrosine and phospho- $\beta$-catenin immunoreactivity in the normal (a) and diabetic (b) placenta. iv, intermediate villi; tv, terminal villi; bar $=12 \mu \mathrm{m}$. a Very weak to negative immunoreactivity in vascular profiles of all types of villi. b Strong anti-phosphotyrosine immunoreactivity is visible in the diabetic vascular profiles; immunoreactivity was localised to the endothelial paracellular clefts. c-e Confocal micrographs showing antiphospho- $\beta$-catenin immunoreactivity in normal and diabetic

placentae. sv, stem villi; tr, trophoblast cells; tv, terminal villi; bar $=12 \mu \mathrm{m}$. c Normal placental vascular profiles showing weak or negative immunoreactivity, with more intense immunostaining of the trophoblast layer. d Micrograph from a diabetic placenta revealing strong immunoreactivity of the vessels and trophoblast. The immunostaining is not exclusive to junctions in the blood vessels. e The more exclusive immunostaining of terminal villous vessels 
Table 3. Relative incidences of vessels that are immunoreactive for various junctional adhesion molecules in placentae from normal and Type 1 diabetic pregnancies

\begin{tabular}{|c|c|c|c|c|c|}
\hline Study group & VE-cadherin & $\beta$-catenin & PECAM-1 & Phospho-tyrosine & Phospho- $\beta$-catenin \\
\hline Normal & $92.9(0.74)$ & $88.6(1.25)$ & $96.6(0.42)$ & $19.2(0.40)$ & $8.0(0.53)$ \\
\hline Type 1 diabetic & $49.4(8.68)$ & $35.5(6.34)$ & $96.3(0.49)$ & $74.3(1.80)$ & $30.3(3.22)$ \\
\hline
\end{tabular}

Values are group means (SEM) expressed as percentages of vascular profiles in each study group. PECAM-1, platelet endothelial adhesion molecule-1; VE-cadherin, vascular endo- thelial cadherin. With the exception of PECAM-1, differences between groups were significant $(p<0.001)$

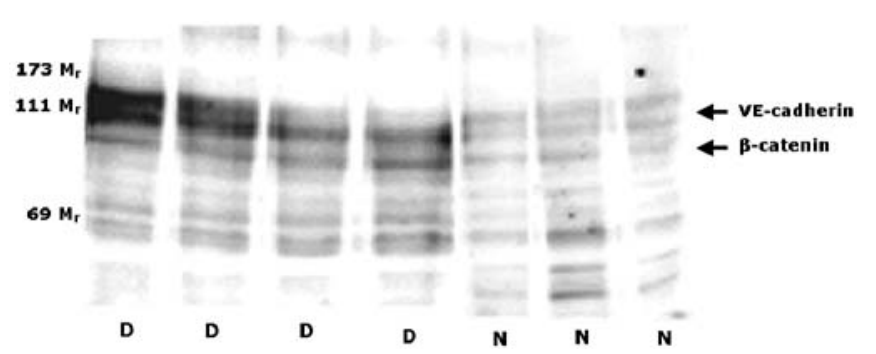

Fig. 5. Expression analyses of phospho-tyrosine in individual Type 1 diabetic (D) and normal (N) placentae. Molecular weight markers are indicated on the left. An increased level of tyrosine phosphorylated proteins, specifically at molecular weights corresponding to those of vascular endothelial (VE)cadherin and $\beta$-catenin, was detected in the diabetic placentae

munostaining of VE-cadherin and $\beta$-catenin. These differences were not found for PECAM-1 (Table 3).

Immunoblots did not reveal any down-regulation of total protein levels for VE-cadherin, $\beta$-catenin and PECAM-1 in the normal group versus the study group (Fig. 3). No differences were seen for $\beta$-actin, which was used as an internal control. The loss of junctional staining of VE-cadherin and $\beta$-catenin was not attributable to changes in protein levels. When the same amounts of placental tissue (rather than protein) were used for immunoblots, there appeared to be an increase in $\beta$-catenin in the Type 1 diabetic samples. However, this may be due to increased amounts of endothelial tissue in the diabetic placenta, since the control protein used in these studies, the endothelial marker thrombomodulin (QBEND 40), showed a similar increase in protein levels (Fig. 3).

Phosphorylation of junctional proteins. Phosphotyrosine immunoreactivity was seen at the paracellular clefts of fetoplacental vessels (Fig. 4). Whilst placentae from normal pregnancies showed only a small percentage of vessels (almost 20\%) with junctional phosphorylation, over $70 \%$ of vessels sampled from diabetic placentae displayed tyrosine phosphorylation of junctional proteins $(p<0.001$; Table 3$)$. Immunoblot analyses revealed increased levels of tyrosine phosphorylated proteins at molecular weights corresponding to those of VE-cadherin and $\beta$-catenin in the diabetic placenta (Fig. 5).
Using monoclonal antibodies specifically targeted to phospho- $\beta$-catenin (serine and threonine residues), we found that in placentae from diabetic pregnancies (Fig. 4) a significantly higher proportion of vessels (increase approximately four-fold) contained phosphorylated $\beta$-catenin at paracellular cleft regions $(p<0.001)$.

Analyses of VEGF. Western blots (with equal protein loading) revealed that VEGF levels were higher in placentae taken from the Type 1 diabetic study group (increased band width and intensities; Fig. 6). Confocal microscopy revealed that whilst VEGF in normal placentae was localised to the trophoblast of terminal villi, VEGF in Type 1 diabetic placentae was localised to the trophoblast and blood vessels contained in terminal, intermediate and stem chorionic villi (Fig. 6).

Analyses of endothelial proliferation. Using a novel fixation protocol suitable for human placental cryosections, there was a five-fold increase in endothelial proliferation in Type 1 diabetes, as demonstrated by the relative incidences of PCNA immunoreactivity (Fig. 7). Increased immunoreactivities of vascular endothelial cells appeared to involve all levels of villous arborisations including intermediate and stem villi (where vessels include arteries, arterioles, veins and post-capillary venules). The increase in PCNA labelling in Type 1 diabetic placentae, combined with the increased QBEND 40 protein levels, is consistent with the increase in the amount of endothelium in these placentae.

Stereological measures of angiogenesis. The combined length of fetoplacental vessels in the normal placenta was found to be $593 \mathrm{~km}$ (SEM $32.2 \mathrm{~km}$ ), whilst that in Type 1 diabetic placentae was $824 \mathrm{~km}$ (SEM $50.0 \mathrm{~km} ; p<0.01$ ). The mean 'diameter' of normal placental microvessels $(12 \mu \mathrm{m}$ [SEM $0.79 \mu \mathrm{m}])$ was not significantly different from that estimated for Type 1 diabetes $(11.8 \mu \mathrm{m}$ [SEM $0.54 \mu \mathrm{m}$ ]). These findings show that enhanced angiogenesis in diabetes was attributable to an increase in total length of vessels without attendant changes in vessel calibre. 

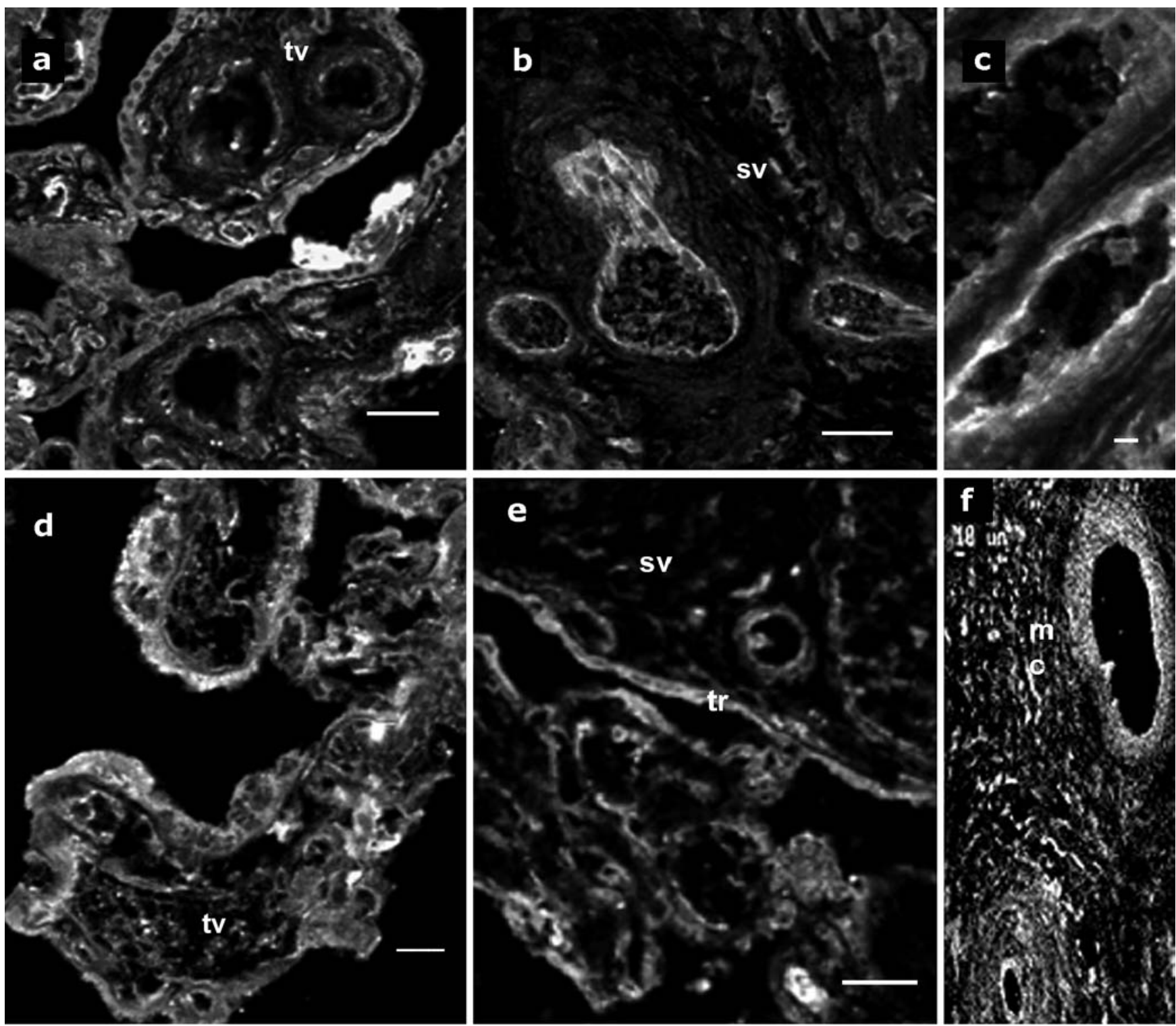

$\mathbf{g}$

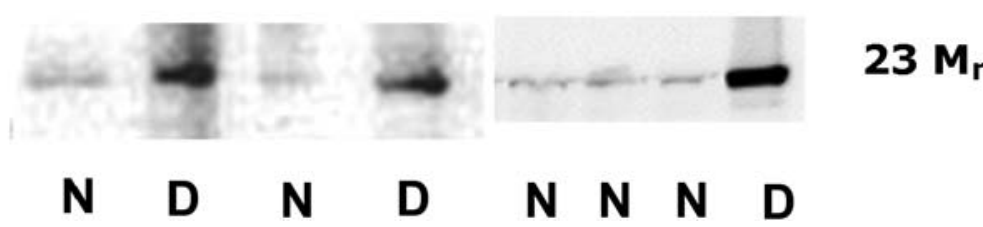

Fig. 6a-g. Confocal micrographs showing immunoreactivity to anti-vascular endothelial growth factor (VEGF). iv, intermediate villi; mc, mural cells of the vascular wall; sv, stem villi; tr, trophoblast cells; tv, terminal villi; bar $=30 \mu \mathrm{m}$ unless otherwise stated. a-c Localisation of VEGF in normal placentae. a VEGF is visible in the trophoblast and endothelium of terminal villi. b Stem villi, showing that localisation predominantly occurs in the endothelial cells. c Endothelial specificity is similar to that in $\mathbf{b}$; bar $=20 \mu \mathrm{m}$. $\mathbf{d}-\mathbf{f}$ In the diabetic placenta the

distribution of VEGF is more extensive; the trophoblast and blood vessels in all villi show immunoreactivity. d VEGF in terminal villi. e VEGF immunoreactivity is visible in the trophoblast and vessels of stem villi. $\mathbf{f}$ Intense staining of perivascular cells (mural cells); bar $=10 \mu \mathrm{m}$. g Expression analyses of VEGF in individual normal (N) and diabetic (D) placentae. Note intensity of band in the lanes loaded with protein from diabetic placentae 

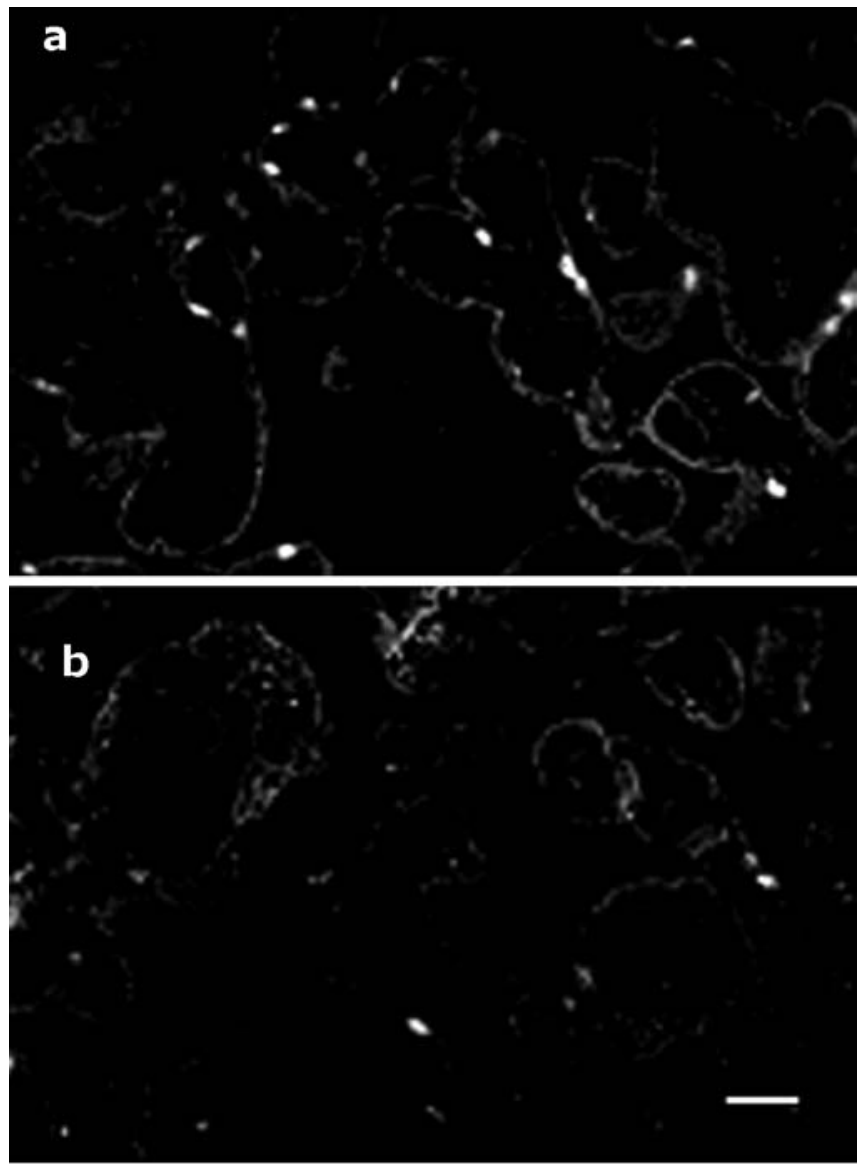

C

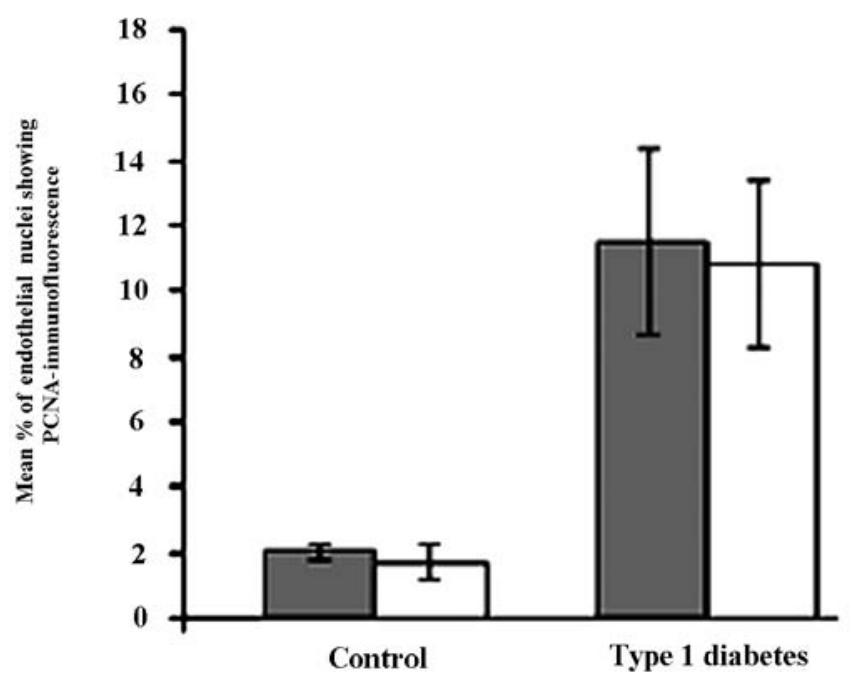

Fig. 7a, b. Fluorescence micrographs showing anti-proliferating cell nuclear antigen (PCNA) activity in the nuclei of the normal and diabetic placenta; bar $=50 \mu \mathrm{m}$. a Higher incidence of nuclear staining in microvessels of the diabetic placenta compared with the normal placenta (b). c Histograph of the mean $\%$ of endothelial nuclei in the two study groups. Two separate counts (blinded) were done. $p<0.001$
Tracer leakage studies on perfused vessels. In placentae from Type 1 diabetic pregnancies, confocal microscopy of randomly selected villous whole mounts from perfused placental lobules revealed the presence of numerous fluorescent 'hot spots' of TRITC-dextran in the perivascular interstitium of terminal and intermediate villi. In contrast, hot spots were minimal or non-existent in perfused placentae from normal pregnancies (Fig. 8). Analyses of cryo-sections revealed that $90 \%$ of the hot spots were associated with vessels that exhibited down-regulation of junctional VE-cadherin and $\beta$-catenin (Fig. 9). Electron microscopical analyses of Type 1 diabetic placentae revealed no gross abnormalities or endothelial denudation and no evidence of increased endothelial vesicles or transendothelial channels.

Correlation of immunoreactivity with maternal glucose control and duration of disease. Variations in immunoreactivities in the Type 1 diabetic study group led us to examine whether there were any correlations between the percentages of vessels showing perturbation of adherens junctional molecules and maternal glycosylated haemoglobin values. We detected no significant correlations with maternal glucose control or with the duration of disease (number of years before pregnancy).

\section{Discussion}

This study shows that a significant proportion of fetoplacental vessels in pregnancies complicated by preexisting Type 1 diabetes mellitus possess a different adherens junctional phenotype from that seen in normal pregnancies. Vessels in diabetic placentae have highly phosphorylated cell-cell junctions and display a loss of junctional immunoreactivity to VE-cadherin and $\beta$-catenin but not to PECAM- 1 . The down-regulation in surface expression of junctional molecules appears not to be due to the down-regulation of proteins but rather to the loss of proteins from junctional domains (to post-translational events). The molecular changes are accompanied by increases in vascular endothelial cell proliferation and total capillary lengths, confirming that the Type 1 diabetic placenta displays increased capillary angiogenesis driven partly by endothelial proliferation. Indeed, the disturbed molecular profiles probably reflect alterations in vessels undergoing various stages of angiogenesis, including early junctional breakages and later junctional reformation or persistent phosphorylation status. Perturbed targeting of junctional adhesion molecules to plasma membrane domains cannot be excluded. The same vessels are leaky, allowing tracers normally retained in the vascular compartment to extravasate and be trapped in the perivascular interstitium. High levels of placental VEGF may be one of the explanations 

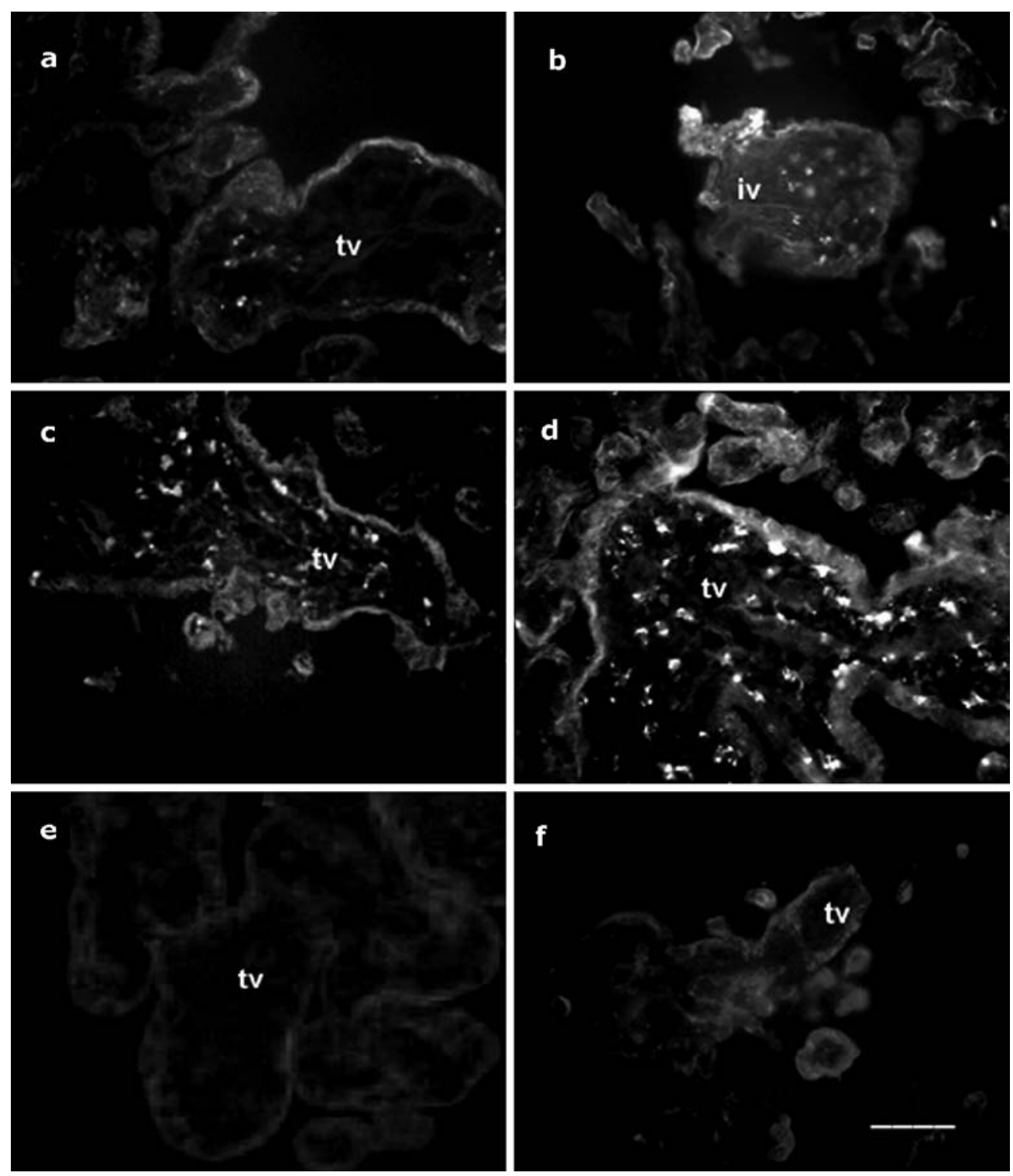

Fig. 8a-f. Confocal scanning micrographs of villous biopsies taken from the microvascular beds of Type 1 diabetic and normal placentae perfused with tetramethylrhodamine isothiocyanate (TRITC)-dextran $(1 \mathrm{mg} / \mathrm{ml})$ for $10 \mathrm{~min}$. iv, intermediate villi; tv, terminal villi; bar $=50 \mu \mathrm{m}$. a-d The tracer trapped in perivascular regions of terminal and intermediate villi of diabetic placenta. e, f No 'hot spots' of extravasated tracers can be seen in normal placenta

for the enhanced angiogenesis, molecular perturbation of adherens junctions and increased vascular permeability.

In Type 1 diabetes with no history of microvascular complications, over $50 \%$ of vessels showed significant loss of paracellular VE-cadherin and $\beta$-catenin immunoreactivity (Table 3). However, no difference in paracellular PECAM-1 immunoreactivity was observed. These in vivo observations reflect those of in vitro studies where declustering of VE-cadherin and $\beta$-catenin, as shown by loss of junctional immunostaining and immunoblotting, resulted in increased proliferation and decreased barrier function $[14,15$, 22]. Transfection of a recombinant VE-cadherin (cytoplasmic domain only) into intact isolated coronary venules has also been seen to result in markedly higher albumin permeability; competition between the recombinant VE-cadherin and the endogenous VEcadherin blocked the association with $\beta$-catenin and the maintenance of junctional integrity and microvascular permeability [30]. Indeed, reassembly of VEcadherin at junctions after calcium chelation has been shown to restore microvascular permeability in pulmonary microvessels [31].

The persistence of paracellular PECAM-1 immunoreactivity in the diabetic placenta is reassuring. In a previous study we have shown that during VEGF-induced angiogenesis, the cell adhesion molecule PECAM-1 demonstrates different dynamics to that of VE-cadherin and $\beta$-catenin; it does not undergo re- 

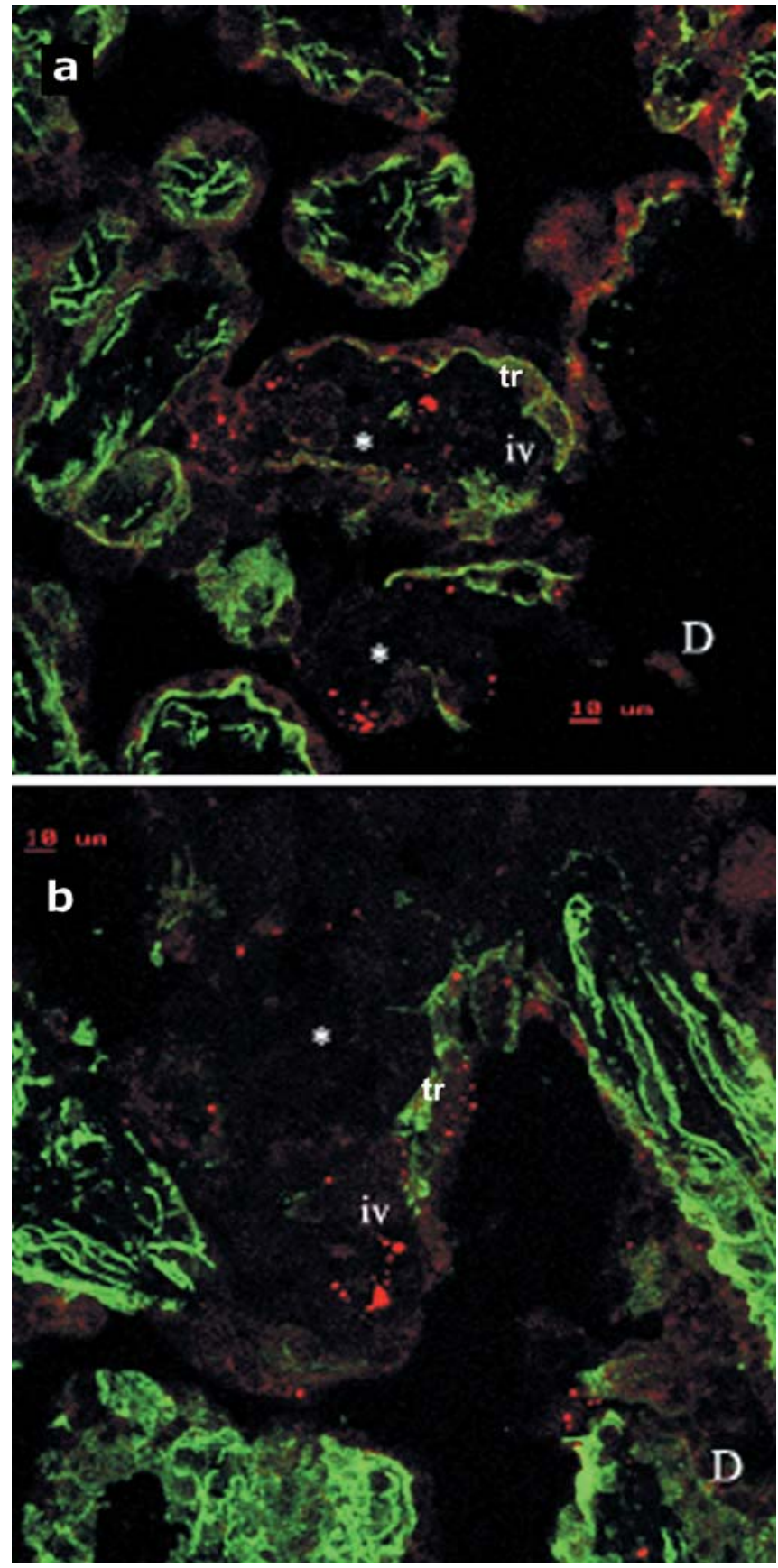

Fig. 9a, b. Confocal scanning micrographs of the Type 1 diabetic placenta perfused with tetramethylrhodamine isothiocyanate (TRITC)-dextran and immunolabelled with anti- $\beta$ catenin. D, diabetic placenta; iv, intermediate villi; tr, trophoblast layer; bar $=10 \mu \mathrm{m}$. Extravasated tracers (red 'hot spots') are only visible in villi where vessels display negative immunoreactivity $(*)$. Note the trophoblast layer of the same villi show $\beta$-catenin immunostaining (green). Tracer hot spots cannot be seen in villi containing vessels with positive junctional $\beta$-catenin immunoreactivity

versible redistribution from junctional regions. This led to the suggestion that after disruption of adherens junctions, maintenance of cell-cell contact remains an important feature of angiogenesis [13]. Recently, PECAM-1 has been shown to promote transcriptional- ly active $\beta$-catenin and to stimulate proliferation [32], with PECAM-1-negative endothelial cells showing localisation of $\beta$-catenin in cell membrane domains. In contrast, in PECAM-1-expressing cells, $\beta$-catenin is localised to the cell membrane and the nucleus [32]. Interestingly, ongoing work in our laboratory shows that human umbilical vein cells isolated from the umbilical cords of the diabetic placenta display increased cytoplasmic and nuclear $\beta$-catenin, with this phenotype being maintained for several passages.

There was a large variation in the percentage of vessels showing loss of VE-cadherin and $\beta$-catenin in the diabetic group (Table 3), unlike the inter-patient variation seen in normal pregnancies. This variation did not correlate with maternal glycaemic control (throughout the different trimesters) or with duration of disease. The values obtained (Table 2) show that maternal glucose levels were reasonably well controlled during pregnancy. Recent work in our laboratories (unpublished data) shows that in cases of maternal Type 1 diabetes, neonatal glycated haemoglobin levels at birth have a negative correlation with junctional immunoreactivity. However, it remains unclear whether this is the cause or the effect. Fetal hyperinsulinaemia in these insulin-treated patients may also be a confounder. Insulin is known to increase the transcapillary escape rate of albumin, although the mechanism behind this has not been elucidated [33]. We did not record maternal hypoglycaemic or hypoxic events during pregnancy. The frequency of the latter may also be more pertinent to the inter-patient variations observed.

The link between hypoxia and VEGF is well established [34], chronic hypoxia being linked directly with up-regulation of VEGF [35]. Erythropoietin regulates erythropoiesis during fetal life, and the stimulus for its production is reduced oxygen partial pressures $[36,37]$. Concentrations of erythropoietin and other haematological values associated with increased erythropoiesis (including haematocrit, haemoglobin concentration and proportion of haemoglobin F) were seen to be higher in cord blood samples including those of pregnancies associated with maternal diabetes mellitus [38]. VEGF can influence the molecular residency and phosphorylation status of junctional adhesion molecules [14, 15], enhancing angiogenesis and promoting vascular leakage [39, 40, 41], whilst it has been shown that the complexing of VEGF receptor-2 with VE-cadherin, $\beta$-catenin and PI3-kinase is required for the endothelial survival function of VEGF $[8,9]$. In our diabetic group over $70 \%$ of vessels showed phospho-tyrosine immunoreactivity at paracellular clefts, suggesting that phosphorylation of cell-cell adhesion molecules and other lateral membrane receptors is a key feature in the Type 1 diabetic placenta. Moreover, immunoblot analyses of the latter revealed high levels of phosphorylated proteins at molecular weights corresponding to those of VE-cadherin 
and $\beta$-catenin. VEGF levels were higher in diabetic placentae, and VEGF localisation was not confined to trophoblast and vascular cells in terminal villi (which contain angiogenic capillaries in normal pregnancies), but extended to stem and intermediate villi in the diabetic group. Interestingly, in these placentae, junctional perturbations were not exclusive to microvessels, and a small percentage of large vessels also showed loss of junctional staining. Ongoing studies in our laboratory show that perfusion of placental microvessels with VEGF $(100 \mathrm{ng} / \mathrm{ml})$ results in loss of junctional immunoreactivity and extravasation of $76-\mathrm{M}_{\mathrm{r}}$ dextrans [42]. This strengthens the hypothesis that increased VEGF levels are part of the mechanism resulting in the junctional perturbations observed in Type 1 diabetic placentae. Although the signalling properties of VE-cadherin and $\beta$-catenin are largely VEGF induced $[9,22]$, the levels of other angiogenic growth factors, such as placental growth factor, basic fibroblast growth factor and angiopoetins 1 and 2, may influence vascular development and maturity in the diabetic placenta and should be monitored $[9,38]$. Differences in the immunostaining intensity of placental VEGF receptor-1 (but not receptor-2) have been reported in cases of Type 1 diabetes [43].

The western blot data in this study showed that total amounts of the adherens junctional proteins were not altered in the diabetic group, unlike their junctional localisation. Here too, we observed some interplacental variation in the total amounts of VEcadherin and $\beta$-catenin protein in both the normal group and the Type 1 diabetic group. However, there were consistently increased levels of VE-cadherin and $\beta$-catenin in the diabetic group. The condition of diabetes during pregnancy appears not to down-regulate these key junctional proteins.

In this study, perfusion of placental microvascular beds revealed that blood vessels in placentae from pregnancies complicated by Type 1 diabetes were leaky, allowing the extravasation of molecules the size of albumin. This is the first demonstration of the permeability of the diabetic human fetoplacental vessels. Trapped tracers or 'hot spots' were found predominantly in intermediate and terminal villi, i.e. microvascular compartments (Fig. 8). There was an extremely high correlation $(>90 \%)$ between fetoplacental vessels showing loss of junctional VE-cadherin and $\beta$-catenin and the presence of extravasated hot spots in perivascular regions (Fig. 9). These observations, in conjunction with those of established studies showing regulation of permeability by adherens junctions in culture $[8,14,16]$ and in retinal, pulmonary, tracheal, placental and coronary microvessels $[12,16,17,30,31,32$, $44,45,46]$ lead us to hypothesise that adherens junctional perturbation in diabetes contributes largely to the observed vascular leakiness. Electron microscopical studies did not reveal the presence of transendothelial channels, the alternate induced transport pathway [47] for inflamed vessels. A sparsity of caveolae and vesicles is found in normal [26] and diabetic placental capillaries (data not shown).

By monitoring endothelial anti-PCNA immunoreactivity in different villous types (stem, intermediate or terminal), we detected cell proliferation at different sites throughout the villous arborisations. Overall, there was an increase of roughly five-fold in the proportion of PCNA-immunolabelled nuclei seen in sections taken from diabetic placentae. Cytotrophoblast (the stem cell compartment of villous trophoblast) in intermediate and terminal villi also displayed antiPCNA immunoreactivity. Stereological analyses confirmed that the combined length of capillaries in peripheral (intermediate plus terminal) villi was significantly greater in diabetic placentae and this supports the increased angiogenesis reported previously in independent studies [2, 4]. These morphometric changes appear to be independent of disease severity $[3,4,5]$.

The findings on increased endothelial proliferation and angiogenesis in Type 1 diabetes are consistent with earlier findings [3] and with the notion that enhanced angiogenesis in diabetic placentae is longitudinal and not accompanied by size-remodelling of endothelial squames [4]. In normal pregnancy [1], angiogenesis and villous development occur by an early phase of branching angiogenesis (formation of new capillary segments) followed by increased nonbranching angiogenesis (formation of longer capillary segments). Present results do not discriminate between these two strategies, but merely reflect the fact that the combined length of all capillary segments is increased in diabetes. They indicate that endothelial cell proliferation contributes to angiogenesis, but provide no information about the roles that endothelial apoptosis and recruitment of circulating endothelial progenitor cells might play in net angiogenesis (the outcome of vessel creation and pruning). In diabetic pregnancies, increased placental endothelial proliferation appears to occur in the same location as that seen in normal pregnancies, i.e. the entire vascular system shows evidence of proliferative activity.

The rather surprising increase in the percentage of vessels $(30 \%)$ showing hyperphosphorylated $\beta$-catenin (at serine 45 and threonine 41 ) in the diabetic placenta (Fig. 4) suggests that controlled increases in proliferation occur in diabetic pregnancies, rather than the uncontrolled increases in proliferation reported in diseases such as cancer $[18,19]$. Increased hyperphosphorylation of $\beta$-catenin would allow degradation of any excess $\beta$-catenin released from adherens junctions [19], thus inhibiting the induced proliferation switch. The percentage of vessels showing phospho- $\beta$-catenin immunoreactivity may reflect the percentage resisting angiogenesis despite the disturbed intrauterine environment.

In gestational diabetes (which affects the latter half of pregnancy, sparing the development stages of vas- 
culogenesis and early angiogenesis) the picture is less clear, since there is junctional perturbation [23] but also evidence for and against enhanced angiogenesis $[23,48]$. Since some of these pregnancies may have included pre-gestational Type 2 diabetes patients, further investigations on gestational diabetes are required to resolve the apparent discrepancies. Recently, a study using three-dimensional visualisation techniques has reported increased longitudinal growth of fetoplacental vessels and enhanced branching angiogenesis in gestational diabetes [49].

In conclusion, we have shown that in Type 1 diabetes (where the processes of vasculogenesis and angiogenesis as well as the establishment and growth of the placental vasculature occur in the diabetic milieu), molecular changes in adherens junctions are more pronounced, and correlate with increases in the proliferation, angiogenesis and permeability of fetoplacental vessels. The higher incidence of leaky vessels is likely to be detrimental to placental function; materno-fetal transport and fetal protection would be compromised, given that the fetal endothelium contributes substantially to transplacental resistance in normal pregnancies. This pathology may explain in part the increased risk of fetal morbidity and abnormal fetal growth in pregnancies complicated by Type 1 diabetes.

Acknowledgements. We wish to thank the Wellcome Trust for funding this project. Yvonne Littler and Tiffany Willmott's assistance with the western blots and Dr F. Siddiqiqui's help with the collection and perfusion of some of the Type 1 placentae is also gratefully acknowledged.

\section{References}

1. Benirschke K, Kaufmann P (2000) Pathology of the human placenta, 4th edn. Springer, New York

2. Mayhew TM (2002) Fetoplacental angiogenesis during gestation is biphasic, longitudinal and occurs by proliferation and remodelling of vascular endothelial cells. Placenta 23:742-750

3. Teasdale F (1983) Histomorphometry of the human placenta in class B diabetes mellitus. Placenta 4:1-12

4. Mayhew TM (2002) Enhanced fetoplacental angiogenesis in pre-gestational diabetes mellitus: the extra growth is exclusively longitudinal and not accompanied by microvascular remodelling. Diabetologia 45:1434-1439

5. Mayhew TM, Sørensen FB, Klebe JG, Jackson MR (1994) Growth and maturation of villi in placentae from wellcontrolled diabetic women. Placenta 15:57-65

6. Sander B, Larsen M, Engler C, Lund-Andersen H, Parving HH (1994) Early changes in diabetic retinopathy: capillary loss and blood-retina barrier permeability in relation to metabolic control. Acta Ophthalmol 72:553-559

7. Dejana E (1996) Endothelial adherens junctions: Implications in the control of vascular permeability and angiogenesis. J Clin Invest 98:1949-1953

8. Carmeliet P, Lampugnani MG, Moons L et al. (1999) Targeted deficiency or cytosolic truncation of the VE-cadherin gene in mice impairs VEGF-mediated endothelial survival and angiogenesis. Cell 98:147-157
9. Carmeliet P, Collen D (2000) Molecular basis of angiogenesis. Role of VEGF and VE-cadherin. Ann NY Acad Sci 902:249-262

10. Leach L, Babawale MO, Anderson M, Lammiman M (2002) Vasculogenesis, angiogenesis and the molecular organisation of endothelial junctions in the early human placenta. J Vasc Res 3:246-259

11. Leach L, Lammiman MJ, Babawale MO et al. (2000) Molecular organization of tight and adherens junctions in the human placental vascular tree. Placenta 21:547-557

12. Leach L, Eaton BM, Westcott EDA, Firth JA (1995) Effect of histamine on endothelial permeability and structure and adhesion molecules of the paracellular junctions of perfused human term placental microvessels. Microvasc Res 50:323-337

13. Wright TJ, Leach L, Shaw PE, Jones P (2002) Dynamics of vascular endothelial-cadherin and $\beta$-catenin localisation by vascular endothelial growth factor-induced angiogenesis in human umbilical vein cells. Exp Cell Res 280:159-168

14. Ilan N, Tucker A, Madri JA (2003) Vascular endothelial growth factor expression, $\beta$-catenin tyrosine phosphorylation, and endothelial proliferative behaviour: a pathway for transformation? Lab Invest 83:1105-1115

15. Esser S, Lampugnani MG, Corada M, Dejana E, Risau W (1998) Vascular endothelial growth factor induces VEcadherin tyrosine phosphorylation in endothelial cells. J Cell Sci 111:1853-1865

16. Kevil CG, Payne DK, Mire E, Alexander JS (1998) Vascular permeability factor/vascular endothelial cell growth factor- mediated permeability occurs through disorganization of endothelial junctional proteins. J Biol Chem 273:15099-15103

17. Antonetti DA, Barber AJ, Khin SK, Lieth E, Tarbell JM, Gardner TW (1998) Vascular permeability in experimental diabetes is associated with reduced endothelial occludin content. Diabetes 47:1953-1959

18. Gottardi CJ, Gumbiner BM (2001) Adhesion signaling: how $\beta$-catenin interacts with its partners. Curr Biol 11:792-794

19. Liu C, Li Y, Semenov M et al. (2002) Control of $\beta$-catenin phosphorylation/degradation by a dual-kinase mechanism. Cell 108:837-847

20. Gory-Faure S, Prandini MH, Pointu H et al. (1999) Role of vascular endothelial cadherin in vascular morphogenesis. Development 126:2093-2102

21. Conacci-Sorrell M, Zhurinsky J, Ben-Ze'ev A (2002) The cadherin-catenin adhesion system in signaling and cancer. J Clin Invest 109:987-991

22. Lampugnani MG, Zanetti A, Corada M et al. (2003) Contact inhibition of VEGF-induced proliferation requires vascular endothelial cadherin, $\beta$-catenin, and the phosphatase DEP-1/CD148. J Cell Biol 161:793-804

23. Babawale MO, Lovat S, Mayhew TM, Lammiman MJ, James DK, Leach L (2000) Effects of gestational diabetes on junctional adhesion molecules in human term placental vasculature. Diabetologia 43:1185-1196

24. Eaton BM, Leach L, Firth JA (1993) Permeability of perfused term human placental microvessels. J Physiol 463:141-155

25. Gardosi J (1997) Customized growth curves. Clin Obstet Gynecol 40:715-722

26. Leach L, Firth JA (1992) Fine structure of the paracellular junctions of terminal villous capillaries in the perfused human placenta. Cell Tissue Res 268:447-452

27. Sasaki K, Kurose A, Ishida Y, Matsuta M (1994) Estimation of S-phase fraction in tumour tissue sections by immunohistochemical staining if PCNA. J Histochem Cytochem 42:957-960 
28. Mayhew TM (1997) Recent applications of the new stereology have thrown fresh light on how the human placenta grows and develops its form. J Microsc 186:155-163

29. Gundersen HJG, Jensen E (1987) The efficiency of systematic sampling in stereology and its prediction. $\mathrm{J}$ Microsc 147:229-263

30. Guo M, Wu M, Granger HJ, Yuan SY (2004) Transference of recombinant VE-cadherin cytoplasmic domain alters endothelial junctional integrity and microvascular permeability. J Physiol 554:78-88

31. Gao X, Kouklis P, Xu N et al. (2000) Reversibility of increased microvessel permeability in response to VE-cadherin disassembly. Am J Physiol Lung Cell Mol Physiol 279:L1218-L1225

32. Biswas P, Canosa S, Schoenfeld J, Schoenfeld D, Tucker A, Madri JA (2003) PECAM-1 promotes $\beta$-catenin accumulation and stimulates endothelial cell proliferation. Biochem Biophys Res Commun 303:212-218

33. Hilsted J, Christensen NJ (1992) Dual effect of insulin on plasma volume and transcapillary albumin transport. Diabetologia 35:99-103

34. Ferrara N, Gerber HP, LeCouter J (2003) The biology of VEGF and its receptors. Nat Med 9:669-676

35. Dor Y, Porat R, Keshet E (2001) Vascular endothelial growth factor and vascular adjustments to perturbation in oxygen hemostasis. Am J Physiol Cell Physiol 280:C1367C1374

36. Caro J, Erslev AJ, Silver R, Miller O, Birgegard G (1982) Erythropoietin production in response to anemia or hypoxia in the newborn rat. Blood 60:984-988

37. Costa-Giomi P, Caro J, Weinmann R (1990) Enhancement by hypoxia of human erythropoietin gene transcription in vitro. J Biol Chem 265:10185-10188

38. Mayhew TM, Charnock-Jones DS, Kaufmann P (2004) Aspects of human fetoplacental vasculogenesis and angiogenesis III. Changes in complicated pregnancies. Placenta 25:127-129
39. Zhang ZG, Zhang L, Jiang Q et al. (2000) VEGF enhances angiogenesis and promotes blood-brain barrier leakage in the ischemic brain. J Clin Invest 106:829-838

40. Thurston G (2002) Complementary actions of VEGF and angiopoetin-1 on blood vessel growth and leakage. J Anat 200:575-580

41. Bates DO, Hillman NJ, Pocok TM, Neal CR (2002) Regulation of microvascular permeability by vascular endothelial growth factors. J Anat 200:581-597

42. Glover V, Leach L (2003) Perfusion of human placental vessels with VEGF: Effect on leakage of $76 \mathrm{kDa}$ dextran and junctional organisation. J Vasc Res 40:306 (Abstract)

43. Helske S, Vuorela P, Carpen O, Hornig C, Weich H, Halmesmaki E (2001) Expression of vascular endothelial growth factor receptors 1, 2 and 3 in placentas from normal and complicated pregnancies. Mol Hum Reprod 7:205-210

44. Ward BJ, Bauman KF, Firth JA (1988) Interendothelial junctions of cardiac capillaries in rats: their structure and permeability properties. Cell Tissue Res 252:57-66

45. Wong RK, Baldwin AL, Heimark RL (1999) Cadherin-5 redistribution at sites of TNF-alpha and IFN-gammainduced permeability in mesenteric venules. Am J Physiol 276:H736-H748

46. McDonald DM (1994) Endothelial gaps and permeability of venules in rat tracheas exposed to inflammatory stimuli. Am J Physiol 266:L61-L83

47. Dvorak AM, Kohn S, Morgan ES, Fox P, Nagy JA, Dvorak HF (1996) The vesiculo-vacuolar organelle (VVO): a distinct endothelial cell structure that provides a transcellular pathway for macromolecular extravasation. J Leukoc Biol 59:100-115

48. Teasdale F (1985) Histomorphometry of the human placenta in class $C$ diabetes mellitus. Placenta 6:69-82

49. Jirkovska M, Kubinova L, Janacek J, Moravcova M, Krejci V, Karen P (2002) Topological properties and spatial organization of villous capillaries in normal and diabetic placentas. J Vasc Res 39:268-278 